\title{
Impact of SLA assimilation in the Sicily Channel Regional Model: model skills and mesoscale features
}

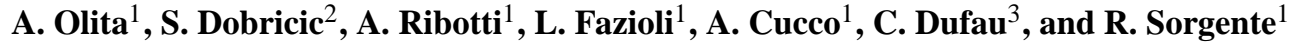 \\ ${ }^{1}$ Consiglio Nazionale delle Ricerche - Istituto per l'Ambiente Marino Costiero, Loc. Sa Mardini, 09170 Oristano, Italy \\ ${ }^{2}$ Centro Euro-Mediterraneo per i Cambiamenti Climatici, Via Aldo Moro 44, 40139 Bologna, Italy \\ ${ }^{3}$ Collecte Localisation Satellites, Space Oceanography Division, Toulouse, France
}

Correspondence to: A. Olita (a.olita@iamc.cnr.it)

Received: 23 January 2012 - Published in Ocean Sci. Discuss.: 1 February 2012

Revised: 7 June 2012 - Accepted: 8 June 2012 - Published: 17 July 2012

\begin{abstract}
The impact of the assimilation of MyOcean sea level anomalies along-track data on the analyses of the Sicily Channel Regional Model was studied. The numerical model has a resolution of $1 / 32^{\circ}$ degrees and is capable to reproduce mesoscale and sub-mesoscale features. The impact of the SLA assimilation is studied by comparing a simulation (SIM, which does not assimilate data) with an analysis (AN) assimilating SLA along-track multi-mission data produced in the framework of MyOcean project. The quality of the analysis was evaluated by computing RMSE of the misfits between analysis background and observations (sea level) before assimilation. A qualitative evaluation of the ability of the analyses to reproduce mesoscale structures is accomplished by comparing model results with ocean colour and SST satellite data, able to detect such features on the ocean surface. CTD profiles allowed to evaluate the impact of the SLA assimilation along the water column. We found a significant improvement for AN solution in terms of SLA RMSE with respect to SIM (the averaged RMSE of AN SLA misfits over 2 years is about $0.5 \mathrm{~cm}$ smaller than SIM). Comparison with CTD data shows a questionable improvement produced by the assimilation process in terms of vertical features: AN is better in temperature while for salinity it gets worse than SIM at the surface. This suggests that a better a-priori description of the vertical error covariances would be desirable. The qualitative comparison of simulation and analyses with synoptic satellite independent data proves that SLA assimilation allows to correctly reproduce some dynamical features (above all the circulation in the Ionian portion of the domain) and mesoscale structures otherwise misplaced or neglected by SIM. Such mesoscale changes also infer that the eddy mo-
\end{abstract}

mentum fluxes (i.e. Reynolds stresses) show major changes in the Ionian area. Changes in Reynolds stresses reflect a different pumping of eastward momentum from the eddy to the mean flow, in turn influencing transports through the channel.

\section{Introduction}

The Sicily Channel (sub-)Regional Model (SCRM Sorgente et al., 2003; Gaberšek et al., 2007; Olita et al., 2007; Sorgente et al., 2011) has produced, since 2003, forecasts and simulations of the central Mediterranean Sea including the southern Tyrrhenian Sea, the Sardinia Channel, the Sicily Channel, the western part of the Ionian Sea and a wide area over the Tunisian and Libyan continental shelves. SCRM is part of the national and Mediterranean networks of operational oceanography, namely GNOO (Italian National Group of Operational Oceanography) and MOON (Mediterranean Operational Oceanography Network).

The modelling system, built with the support of several EU operational oceanography projects (MFSPP, MFSTEP, ECOOP, MyOcean), covers a crucial area of the Mediterranean Sea as the Sicily Channel governs the exchanges of water masses between eastern and western Mediterranean sub-basins (Manzella et al., 1988). The capability to resolve mesoscale dynamics in such an area is of crucial importance for a correct representation of the water flows as eddies can mediate the transport of surface and even intermediate water masses, namely the Levantine Intermediate Waters (e.g. Astraldi et al., 1996, 1999). 
The SCRM system accounts for four main parts: (a) finite difference numerical model simulating the hydrodynamics, forced with appropriate atmospheric fields; (b) observational platform retrieving data for assimilation and cal-val activities; (c) data assimilation scheme(s) merging the information coming from model and observations, providing the best estimate of the true state; (d) web-based interfaces and visualization tools for intermediate and final users. Up to now, the SCRM did not encompass any sophisticated assimilation scheme, as it relied on simple methods for incorporating observations on the numerical solution like the relaxation of heat fluxes to the satellite-observed sea surface temperature (SST) or water fluxes to the climatological salinity. In the present work, we show the results of the first implementation of a 3-D variational assimilation scheme in the SCRM and the impact of the assimilation of sea level anomaly (SLA) along-track MyOcean V1 data on such a system. Satellite SLA is one of the most important data sources (together with satellite SST and in situ profiles) today available for assimilation in ocean numerical models.

To accurately evaluate the impact of SLA assimilation, we performed two interannual experiments covering the period 2008-2009: a reference run (free simulation) and an analysis assimilating the SLA along-track MyOcean data. We quantitatively evaluated the results through basic statistics using SLA and CTD data but, as we are especially interested to observe how the assimilation can improve the dynamic solution of the model and its reproduction of mesoscale features, we also accomplished a qualitative comparison using synoptic (single swaths) satellite observations (SST and ocean colour) capable to detect the footprints of mesoscale structures (eddies and meanders) on the area. In Sect. 2, the numerical model setup, the assimilation scheme and the data used for assimilation and for validation are described. Results are presented and discussed in Sect. 3, while conclusions are drawn in section 4 .

\section{Methods and data}

To evaluate the impact of SLA assimilation, a parallel experiment has been performed: a simulation (SIM, set-up similarly to the current operational SCRM hindcast) that does not assimilate anything, and an analysis (AN) assimilating V1 MyOcean along-track SLA data. The two experiments are carried out for a period of two years, from 15 January 2008 to 15 January 2010. The experiments encompass the use of (1) numerical model, (2) data assimilation (DA) scheme, (3) data for assimilation and validation of model results.

\subsection{Numerical system}

SCRM is a free surface three-dimensional primitive equation finite difference hydrodynamic model based on the Princeton Ocean Model (Blumberg and Mellor, 1987). It solves the equations of continuity, motion, conservation of temperature, salinity and assumes hydrostatic and Boussinesq approximation. It uses the Mellor and Yamada (1982) turbulence closure scheme, while the horizontal viscosity terms are provided by the Smagorinsky parameterization (Smagorinsky, 1993). The model domain is $9^{\circ} \mathrm{E}$ to $17^{\circ} \mathrm{E}$ and $31^{\circ} \mathrm{N}$ to $39.50^{\circ} \mathrm{N}$ with a horizontal resolution of $1 / 32^{\circ}(\sim 3.5 \mathrm{~km})$. In the vertical dimension, it uses 30 sigma levels, denser at the surface following a logarithmic distribution. The external time step is set to $4 \mathrm{~s}$, the internal to $120 \mathrm{~s}$. The model bathymetry is the US Navy Digital Bathymetric DatabaseDBDB 1 at $1 / 60^{\circ}$, interpolated on the model grid. The minimum depth is set to $5 \mathrm{~m}$.

The model has been initialized using dynamically balanced analyse fields from the $1 / 16^{\circ}$ coarse operational model of the Mediterranean Sea MFS1671 (Tonani et al., 2009) through an innovative tool based on the Variational Initialization and Forcing Platform (VIFOP, Auclair et al., 2000; Gaberšek et al., 2007). This tool reduces spin-up times and improves the fields at boundaries by filtering out the high frequency noise (Gaberšek et al., 2007). MFS1671 also provides boundary conditions for the present experimental setup, through a simple off-line, one-way, asynchronous nesting as described in detail in Sorgente et al. (2003). Surface fluxes, computed through the bulk formulae of Castellari et al. (1998), use the 6-hourly atmospheric analyses from European Centre for Medium range Weather Forecast (ECMWF) at $0.25^{\circ}$ of resolution. The parameters used are the $10 \mathrm{~m}$ wind, the $2 \mathrm{~m}$ air temperature, the cloud cover, dewpoint temperature and the atmospheric pressure.

\subsection{Data assimilation scheme and analysis cycle}

The data assimilation is accomplished through the 3-D variational scheme named OceanVar (Dobricic and Pinardi, 2008). The OceanVar finds the minimum of the following cost function:

$J=\frac{1}{2}\left(\mathbf{x}-\mathbf{x}_{b}\right)^{T} \mathbf{B}^{-1}\left(\mathbf{x}-\mathbf{x}_{b}\right)+\frac{1}{2}(\mathbf{H}(\mathbf{x})-\mathbf{y})^{T} \mathbf{R}^{-1}(\mathbf{H}(\mathbf{x})-\mathbf{y}),(1)$

where $\mathbf{x}$ and $\mathbf{x}_{b}$ are respectively the analysis and background (first guess) state vectors (containing temperature, salinity, and velocity components, three-dimensional fields and the surface elevation bidimensional field), $\mathbf{B}$ and $\mathbf{R}$ the background and observational error covariance matrices, $\mathbf{H}$ is the linearized observational operator and $\mathbf{y}$ is the observational state vector. The observational operator is evaluated for $\mathbf{x}=\mathbf{x}_{b}$. The cost function is minimized using the control vector:

$\mathbf{v}=\mathbf{V}^{+}\left(\mathbf{x}-\mathbf{x}_{b}\right)$,

where the superscript "+" indicates the generalized inverse matrix and $\mathbf{V}$ is the square root of $\mathbf{B}$ :

$\mathbf{B}=\mathbf{V} \mathbf{V}^{T}$ 


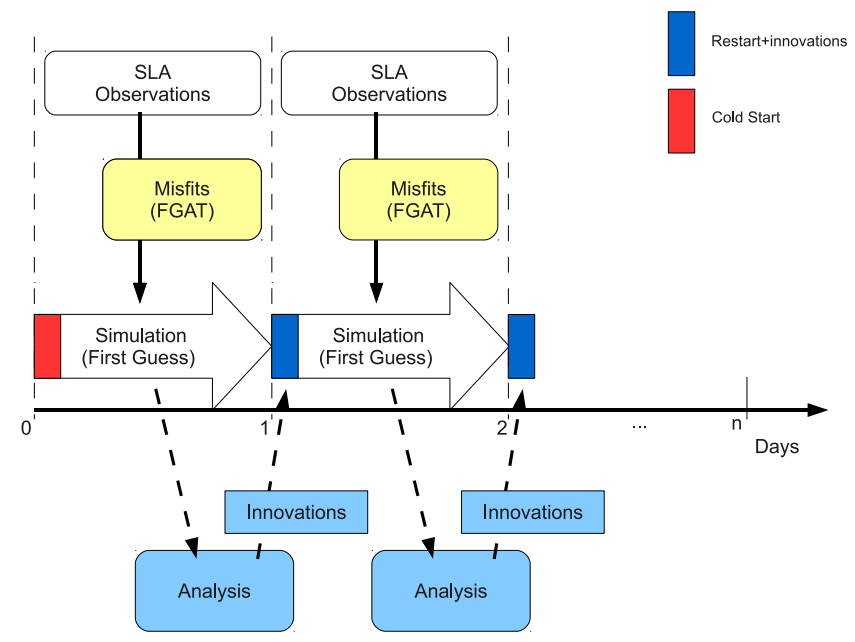

Fig. 1. Daily analyses cycle scheme. FGAT is the First Guess at Appropriate Time method for misfits calculation.

In this specific application of the 3-D variational scheme, the matrix $\mathbf{V}$ is modelled as sequence of linear operators:

$\mathbf{V}=\mathbf{V}_{D} \mathbf{V}_{U V} \mathbf{V}_{\eta} \mathbf{V}_{H} \mathbf{V}_{V}$

where operator $\mathbf{V}_{D}$ applies a divergence damping filter to correct features near the shorelines, $\mathbf{V}_{U V}$ computes velocities from surface height, temperature $(T)$ and salinity $(S)$, $\mathbf{V}_{\eta}$ computes free surface elevation error from $T$ and $S, \mathbf{V}_{H}$ applies the horizontal Gaussian covariances to $T$ and $S, \mathbf{V}_{V}$ reconstructs the vertical profiles of $T$ and $S$ from the apriori computed empirical orthogonal functions (EOFs). In the OceanVar, the vertical covariances are represented by the EOFs of surface elevation, $T$ and $S$. The EOFs are computed on the basis of an already existing interannual simulation. For each new estimation of the cost function, the vector $\mathbf{v}$ multiplies expansion coefficients and EOFs and transforms them into corrections of T, $S$ and surface elevation. In practice, EOFs constitute a $T-S$ constraint on the vertical dimension. For further details about the OceanVar (linear operators description, numerical minimization algorithm), please see Dobricic and Pinardi (2008). The data are assimilated in a daily analysis cycle, schematized in Fig.1. In practice, the simulation providing the analysis background simulates one day per analysis cycle. The misfits are computed during the model integration at the exact time of the available SLA observations (Dobricic et al., 2007, First Guess at Appropriate Time method, FGAT). At the end of the integration, the analysis is done with the OceanVar software which finds the minima of the cost function and computes the innovations that will be applied at the model solution at the begin of the following analysis cycle.

\subsection{Data and analysis}

The assimilated data is the along-track (AT) delayed time (DT) SLA V1 MyOcean data produced and distributed by CLS (Collecte Localisation Satellites). The altimetric data have been collected by Jason-1, Jason-2, TOPEX/Poseidon, Envisat and Geosat Follow-On (G2) satellites. The use of multi-mission altimeter data for assimilation purposes in Mediterranean was proven to have a positive impact on the analyses (Pujol et al., 2010). Details about reprocessing changes, and differences from the elder V0 version, can be found at http://www.aviso.oceanobs.com/fr/donnees/ informations-sur-les-produits/duacs/presentation/updates/ index.html\#c7681. According to the cited documentation, the major improvements of V1 products are orbit error reduction and long wavelength error minimization, and presence of data closer to the coast.

SLA data are also assimilated by the coarse model providing boundary conditions to SCRM. For one-way nesting scheme as in our implementation, Vandenbulcke et al. (2006) proved that the SLA signal coming from coarse model through the boundaries (assimilating SLA) is not sufficient to transfer the information throughout the whole nested high resolution domain, above all considering that SLA information concerns mesoscale features that can be resolved only by high resolution model. On the contrary, when the approach is a two-way nesting, the best results are reached assimilating data in the nested model only.

The misfits between the background (first guess) and the observations, calculated at each iteration of the assimilation process on a daily window, are used to assess the overall quality of the experiments. The average of the misfits along the track is removed in order to remove the error due to the steric effects, while a signal is present in the altimetric data. The root mean square error (RMSE) of misfits is computed both for AN and SIM. To reassure the reader about the independence of the data used for this quantitative assessment, it is important to underline that the SLA misfits are calculated before the data are actually assimilated in the analyses.

In situ measurements of temperature and salinity collected through CTD samplings are used to evaluate the impact of the assimilation on sub-surface and deep layers. In order to skip partially the space-time mismatching issue between simulated and measured profiles (CTD profiles represent a point measurement while a model grid element can be thought as a region of about $12 \mathrm{~km}^{2}$ ), the four grid point surrounding each sampling point was interpolated to the CTD profile location and depth, thus obtaining a corresponding simulated profile. The CTD data have been collected during two oceanographic cruises conducted, on board the the R/V Urania, in August and November 2009. We also qualitatively evaluated the impact of the assimilation in terms of change/improvement in the reproduction of surface features by comparing the surface analyse fields with synoptic observations of the sea state provided by optic and infrared satellite images. In order to do 
this, MODIS AQUA and TERRA level-2 data of chlorophylla concentration and SST were used to compare the footprints of mesoscale features with those of the two numerical experiments.

\section{Results and discussion}

\subsection{Assessment of the surface features}

As previously pointed out, the first evaluation of the quality of the analyses was done through a comparison of the RMSE of the SLA misfits. In top panel of Fig. 2, the weekly time series of the RMSE of SLA misfits for SIM and AN experiments are shown. The RMSEs have been weekly averaged in order to simplify the reading of the figure, as the daily series have many gaps due to the absence of valid data on some days (about $10 \%$ of the dataset). The time-averaged RMSE over the two years of integration is $3.68 \mathrm{~cm}$ and $4.20 \mathrm{~cm}$ for AN and SIM respectively. The central panel of Fig. 2 shows the difference between the two series shown in top panel, while bottom panel shows the weekly number of observations assimilated during the analysis. In the bottom panel are also indicated, with red squares, the dates when there were no data to be assimilated. Biases (misfits averages) are not shown as they are proxy to zero. This is because misfits averages along each satellite track are removed for misfits computation, mainly in order to remove the steric signal (which is not modelled). It is noteworthy that the high-frequency signal drawn by the RMSE time series (top panel) seems related to the large variability on the number and availability of data to be assimilated (bottom panel), in turn firstly depending on the number and position of the orbital passes of the satellite altimeters over the model domain. SIM RMSE increases as the simulation proceeds: this positive trend was strongly corrected in AN experiment. The drift of SIM experiment seems faster during the first 6-7 months, after which it slows down significantly.

The distribution of the misfits for SIM and AN experiments is shown in Fig. 3. The maps are generated from the along-track misfits calculated for the whole period, then interpolated on the model grid. As can be seen by comparing the two maps, the main corrections due to the assimilation process are concentrated in the Ionian area, east of Malta and some spots in the Sardinian Channel.

To better understand the difference between the two experiments argued by comparing the SLA RMSE residuals, a visual comparison of the simulated features with those detectable through satellite-independent observations (MODIS SST and chlorophyll-a data) was performed. The selection of the dates for such a comparison was done as function of the cloud cover (limiting the optical and infrared satellite measurements) and trying to emphasize the differences between the experiments, as argued by RMSE time series and maps. Fig. 4 shows the salinity fields of AN and SIM for 22 April 2008 (daily average) compared to the MODIS chlorophyll-a concentration field for the same date. In this case, we used an optical product (chlorophyll-a) instead of the SST product because of the small thermic gradient between Atlantic waters and resident water masses during this period of the year. The main differences are related to the different behaviour of the Atlantic water (AW) crossing the Sardinian and Sicilian Channel, detected in model results by salinity ranging from 37.5 to $37.8 p s u$. In SIM, the AW, crossing the Sardinian Channel $\left(10^{\circ} \mathrm{E}\right)$, is squeezed against the Tunisian coast and proceeds straight eastward, while it shows a meandering behaviour in AN. The satellite image shows the clear signature of sub-mesoscale anticyclonic meanders approximately located at $10^{\circ} \mathrm{E}$ and $38^{\circ} \mathrm{N}$. The signature can also be observed in both the analyse experiments. Another difference can be noticed in the AW flowing along the southern Sicilian Coast. This branch of the AW reaches the Island of Malta $\left(14^{\circ} \mathrm{E}\right.$ and $\left.36^{\circ} \mathrm{N}\right)$ in SIM, while for AN experiment it does not reach such a longitude, forming a more defined meridional front with resident waters of Ionian origin. The presence of such a small frontal area is also suggested by the satellite chlorophyll-a observation (which is known to be well correlated to salinity and density fronts). In other words, both satellite and AN suggest that the AW does not properly form a northern branch along the southern Sicilian coast. This is also in agreement with literature (e.g. Robinson et al., 1999; Sorgente et al., 2011) that describes this branch, in which transport is associated with the Atlantic Ionian Stream (AIS), as a typical summer feature that reduces its intensity during late autumn, winter and early spring in favour of an increase of the AW flow along the African coast spreading over the Tunisian shelf.

Figure 5 shows surface elevation model and analyse fields for 18 October 2008 compared to satellite SST signature. The big difference is the large meander that the AIS, the jet current flowing eastward along the southern Sicilian coast, draws northward once overpassed the SE margin of the Sicily Island: this meander is only present in SIM, while it disappears in the analysis. Satellite imagery confirms the absence of this feature east of Sicilian east coast. On the contrary, the AIS once passed the Ionian Shelf break at about $15.5^{\circ} \mathrm{E}$ and accomplishes a wide cyclonic meander (both in satellite and analyse fields). Further, the upwelling area south of Sicily already present in SIM is still maintained and enhanced in AN (where it is associated with the presence and formation of a strong cyclonic meander of the AIS at about $13^{\circ} \mathrm{E}-$ $36.5^{\circ} \mathrm{N}$ ). We observed that the northward overshooting of the AIS along the eastern coast of Sicily is the main structure constantly reproduced by the SIM and corrected in the analyses. To further investigate this feature, corresponding to the area subject to the main correction by the assimilation, in Fig. 6 the SST-simulated/analysed fields for July 17th, 2009 are shown, zoomed in on the area of interest, and compared to the satellite SST. Here, SIM shows the wide anticyclonic meander in the Ionian Sea that is strongly corrected by the 

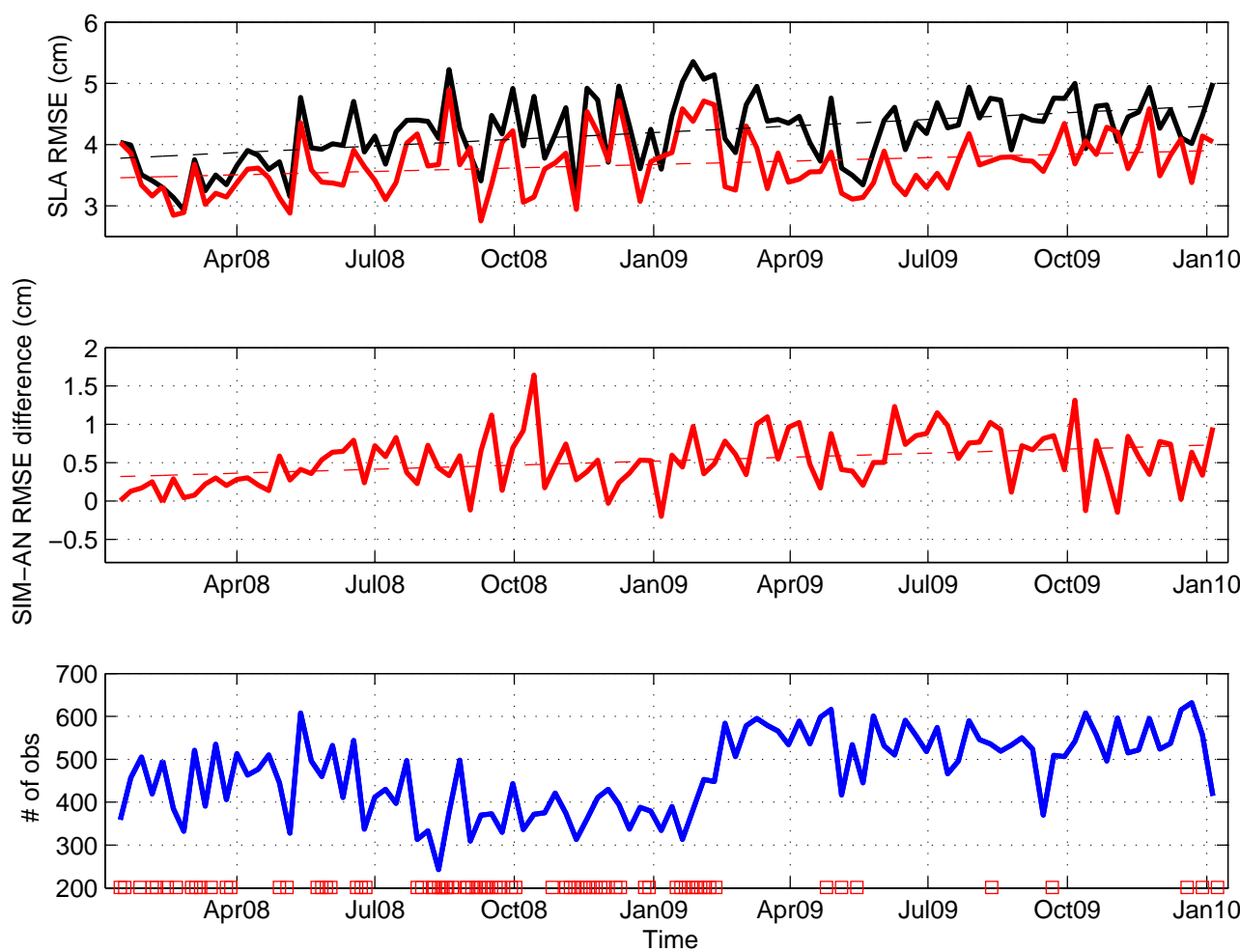

Fig. 2. Top panel: RMSE of SLA misfits with observations for AN background (red) and SIM (black). The respective trends are also plotted (dashed lines); Central panel: Differences between RMSE curves: SIM-AN and relative trend; Bottom panel: number of observations assimilated. Days with no observations to be assimilated are also indicated along the $\mathrm{x}$-axis with red squares. RMSE values are weekly averages while the weekly sum was calculated for the number of observations.
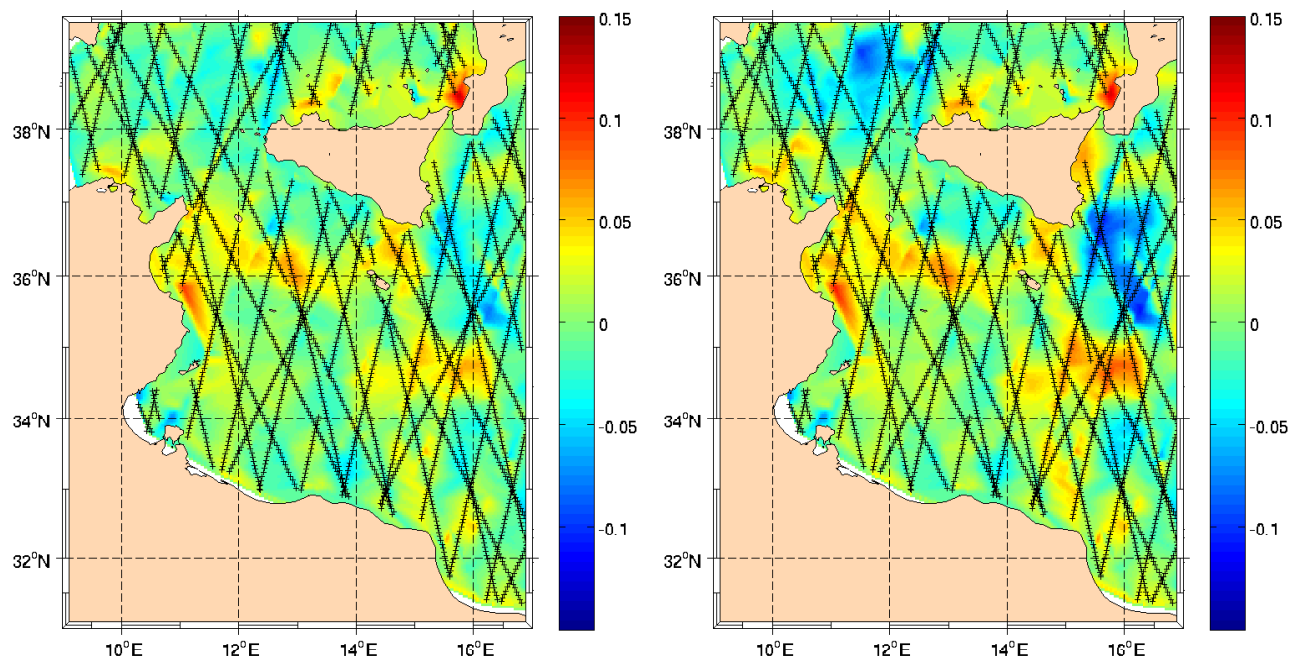

Fig. 3. Misfits for AN background (left) and SIM (right). The maps are obtained through linear interpolation of the misfits between model and Along Track SLA V1 data, whose position is also shown.

SLA assimilation; the AN field shows this structure lowered in latitude and forming a coherent anticyclone. The same can be observed in the satellite SST image that clearly shows the anticyclone approximately at the same location and with a similar shape and size.

\subsection{Eddy momentum fluxes and volume transports}

Such differences between AN and SIM are well evidenced in terms of eddy momentum fluxes, i.e. Reynolds stress (e.g. Morrow et al., 1994; Greatbatch et al., 2010). The 


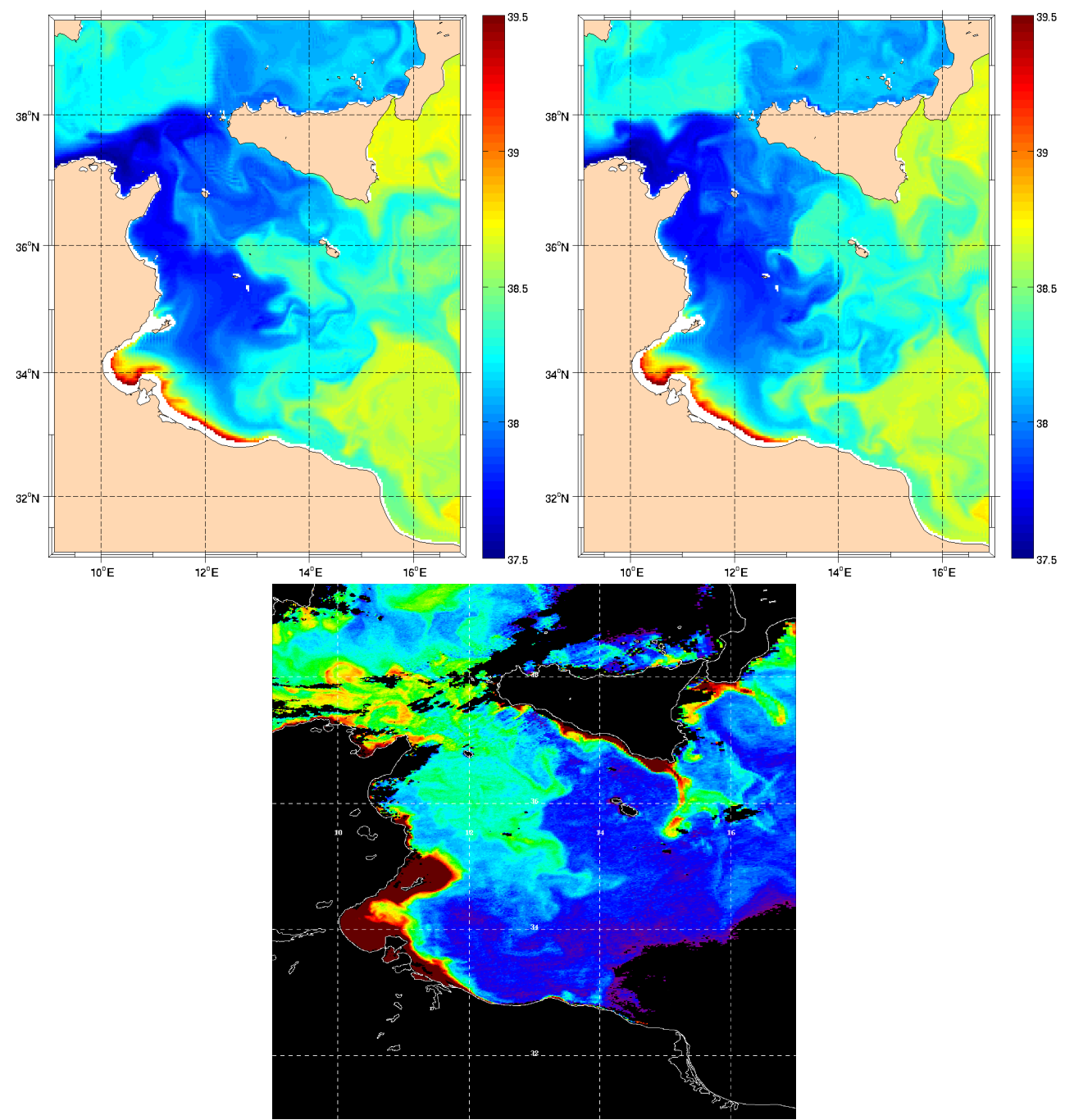

Fig. 4. 22 April 2008. Salinity (psu) for SIM (left) and AN (right). Bottom panel shows satellite chlorophyll-a from MODIS-AQUA.

Reynolds stress co-variance component is calculated as $<$ $u^{\prime} v^{\prime}>$, where $u^{\prime}$ is the fluctuating (time-dependent) part of the velocity $u$ (same for $v$ ), decomposed as $u=U+u^{\prime}$, where $U$ is the time-independent part of the flow; angle brackets $(<>)$ indicate a long-term time average. In our case, Reynolds stress co-variance is used to better understand how and where the assimilation of SLA, which is supposed to infer above all on mesoscale circulation, can bring important changes on the eddy/mean flow interactions. The meridional gradient of the $\left\langle u^{\prime} v^{\prime}\right\rangle$, accordingly with Ducet and Le Traon (2001), is often used as descriptor of the contribution of the eddy field to the mean flow for zonal currents.

Top panels of Fig. 7, representing Reynolds stress covariance term for AN (left) and SIM (right), show a quite similar distribution of the stress patches, with the exception of the area east of Sicily where the assimilation infers major changes on the sea level field. Both AN and SIM $<u^{\prime} v^{\prime}>$ maps show narrow areas (along the main AW path, north of the African coast and along the southern Sicily coast) where $\left.<u^{\prime} v^{\prime}\right\rangle$ covariances are positive south of the stream and negative north of stream, creating convergence of eastward momentum into the currents (namely the Algerian Current and the Atlantic Ionian Stream). Another evident feature, common to both the experiments even if with different magnitude, is the elongated red (positive values) patch west of Sicily: here the AC splits into two branches and the bifurcating Tyrrhenian Current (Sorgente et al., 2011) starts its path along the northern Sicily coast. Positive values as well the elongated shape of this feature indicate that the direction varies preferentially between NE and SE. Notwithstanding the similar distribution of the patches cited above, the stress values significantly change in many parts of the domain. The bottom panel of Fig. 7 shows the Reynolds stress difference between the two experiments (AN-SIM). This figure put in evidence well that covariance stress values significantly change between the two experiments. In particular 


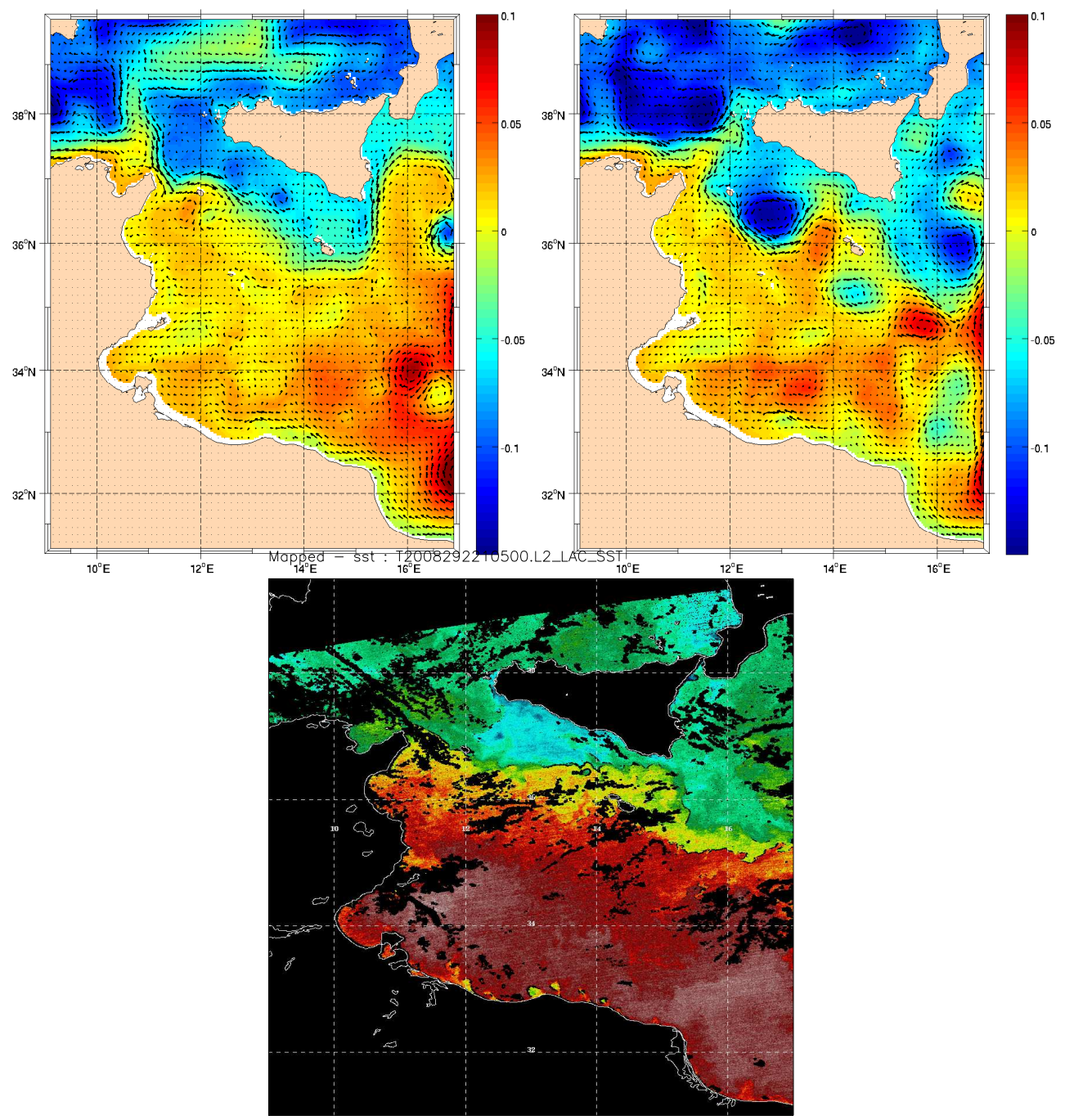

Fig. 5. 18 October 2008. Free surface elevation in cm for SIM (left) and AN (right). Bottom panel shows satellite SST.

in the Ionian region, the assimilation of AT SLA drastically changed the $<u^{\prime} v^{\prime}>$ term. In particular, SIM shows large and positive values in correspondence of the anticyclonic meander of the AIS along the eastern coast of Sicily. A strong Reynolds stress signature is visible, in SIM, both in the northward part of the stream as well on its southward branch. On the contrary, analyses show a distribution of the stress covariance that alternates positive and negative values over a quasi-circular area, a pattern compatible with the presence of a coherent eddy structure, as already argued by analysing synoptic satellite data. This pattern is associated with smaller Reynolds stress values than for SIM. Conversely, the general impact of SLA assimilation all over the rest of the domain is an increase of the covariance stress term.

Such changes on the turbulent part of the horizontal flow have only a relative influence on the transport across the channel. At the three open boundaries $(\mathrm{E}, \mathrm{W}, \mathrm{N})$, the net transport does not change much, because the open boundary con- ditions (OBC) constrain the SCRM net transport to be equal to the coarse model. Nevertheless, noticeable differences can be observed by analysing eastward ( $\sim$ westward) transports only, above all if they are computed sufficiently far from the boundaries, for example at the the Sicily Strait (SicilyTunisia section). The yearly averaged eastward transport at the Sicily-Tunisia section is $1.66 \mathrm{~Sv}$ for SIM and $1.71 \mathrm{~Sv}$ for AN experiment in 2008, while in 2009 the yearly average is $1.77 \mathrm{~Sv}$ for SIM and $1.87 \mathrm{~Sv}$ for AN. These transport estimates are larger than those obtained from experimental measurement (e.g. Astraldi et al., 1996; Beranger et al., 2004, of the order of about $1 \mathrm{~Sv}$ ), as well slightly larger than the $1.4 \mathrm{~Sv}$ 9-year-averaged modelling estimates of Pinardi et al. (1997). Such differences with literature can be attributed to the ability of the model to resolve mesoscale and sub-mesoscale features allowing cross-section recirculation driven by eddies, in turn increasing eastward (westward) flows (while the net remains substantially unchanged). Despite that the yearly 


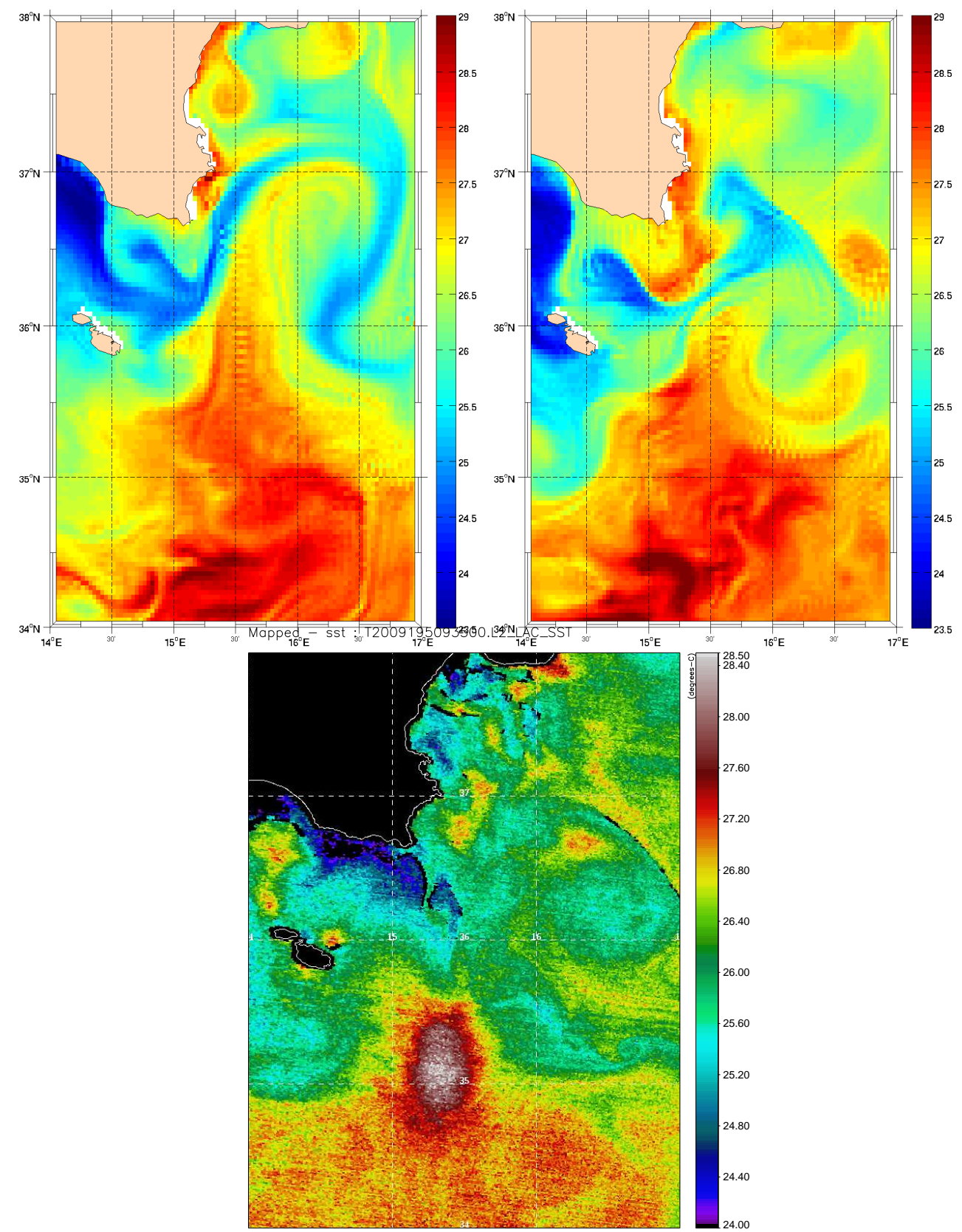

Fig. 6. 14 July 2009. SST $\left(C^{\circ}\right)$ for SIM (left) and AN (right). Bottom panel shows satellite SST.

averages do not change considerably with the assimilation, the daily time series of Fig. 8 show noticeable differences in terms of relative and absolute maxima. Major differences can be observed for both the years in late summer - autumn. Absolute maximum for AN series is about $2.6 \mathrm{~Sv}$, while SIM records an absolute maximum of about $2.3 \mathrm{~Sv}$.

\subsection{Vertical features}

The overall impact of the SLA assimilation on reproducing the water column properties was evaluated by comparing the simulated/analysed salinity and temperature with those col- lected by CTD during two oceanographic cruises conducted in August and November 2009. Figure 9 shows the RMSE between modelled profiles of AN and SIM experiments and observations for temperature (left) and salinity. In August the model solution is improved by the assimilation of $\mathrm{V} 1$ data above all between 100 and $300 \mathrm{~m}$ for both $T$ and $S$, while at surface the analyses show worse performances in salinity. The salinity maximum, which in the Sicily Channel is related to the LIW flow, is systematically underestimated by SIM, while in AN the salinity range is wider, reaching higher and more realistic maxima. This is one of the reasons why 

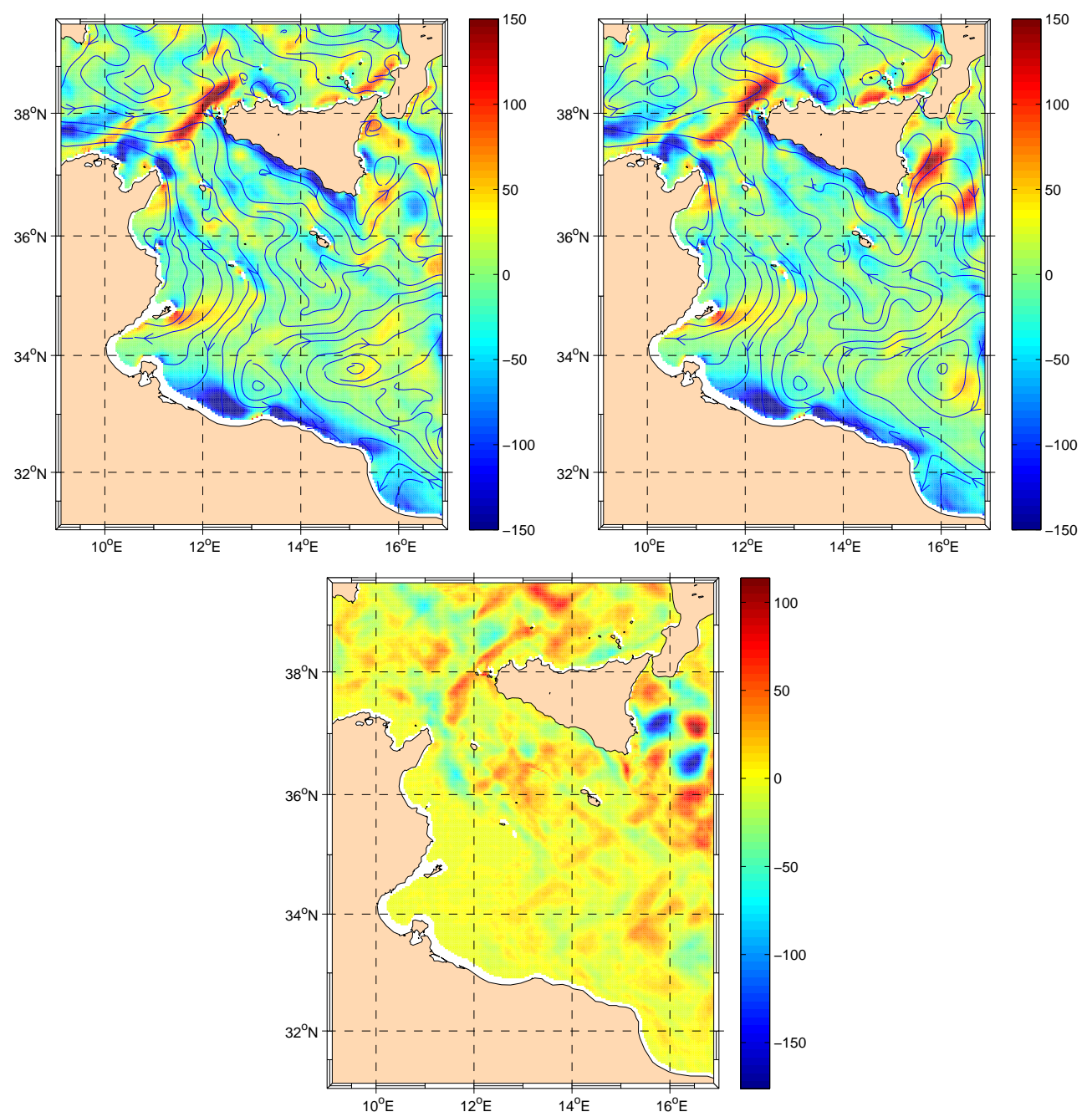

Fig. 7. Reynolds stress covariance $<u^{\prime} v^{\prime}>$ for AN (left) and SIM (right), with streamlines of the mean flow overplotted. Bottom panel shows the difference AN-SIM. Units are $\mathrm{cm}^{2} / \mathrm{s}^{2}$.

the major improvement that the assimilation produces in the vertical dimension is located at intermediate depths. November 2009 cruise draws a similar situation in terms of impact produced by the assimilation on the vertical. The main difference is that salinity is always worse for the top 200 meters for analyses. At higher depths, no significant difference between simulated and analysed profiles can be noticed for salinity . On the other hand, temperature shows more or less the same improvement as observed for the former cruise.

We would like to underline that big improvements were not expected in terms of vertical profiles because no profile data were assimilated in the analyses. Therefore, the corrections in the vertical structure of the water column are only a function of the free surface corrections and their covariance with $T$ and $S$ vertical profiles, as prescribed by the vertical background error covariance matrix calculated through EOFs. In other words, the shape of single profiles (see in Fig. 10 an example) is generally improved by the SLA as- similation, in some cases in a very significant way, even if RMSE or a bias were to result even in an increase at some depth for the salinity. This is clear in Fig. 10 where it is evident that AN better reproduces the general shape of the observed profile: the difference is that for temperature also RMSE and bias are reduced with respect to SIM, while for salinity (at least in the top layers), the bias is increased. The salinity minimum at about $-60 \mathrm{~m}$ is completely neglected by SIM (that better matches the value), while AN (nevertheless a larger bias) is able to reproduce this minimum. This particular impact of the assimilation on the vertical dimension deserves a further insight: new experiments will be conducted with a new EOF set, a different parameterization of diffusivity coefficients and making use of a larger in situ dataset for the validation of vertical profiles. 


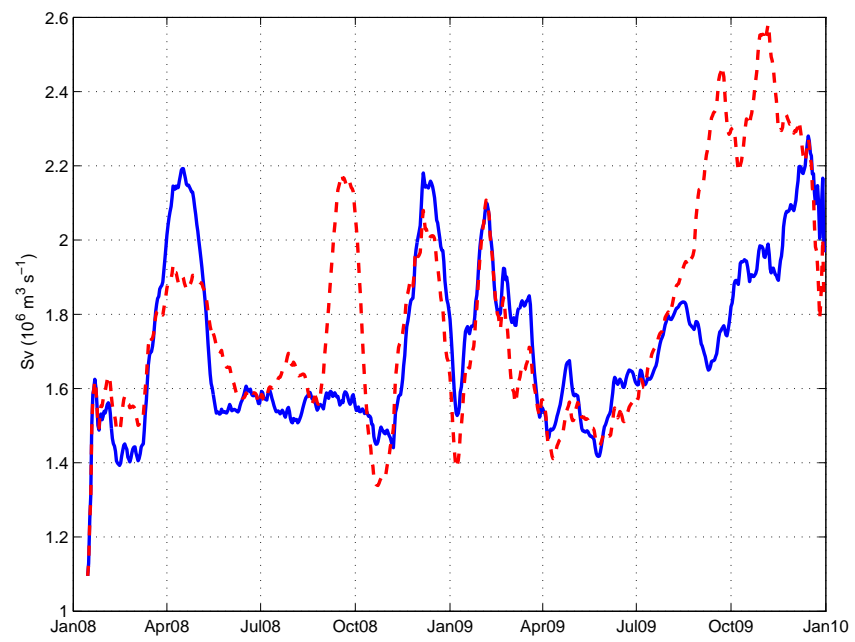

Fig. 8. Eastward transport $(S v)$ at the Sicily Strait (daily time series smoothed through 30-days moving average) for AN (red dashed line) and SIM (blue full line).

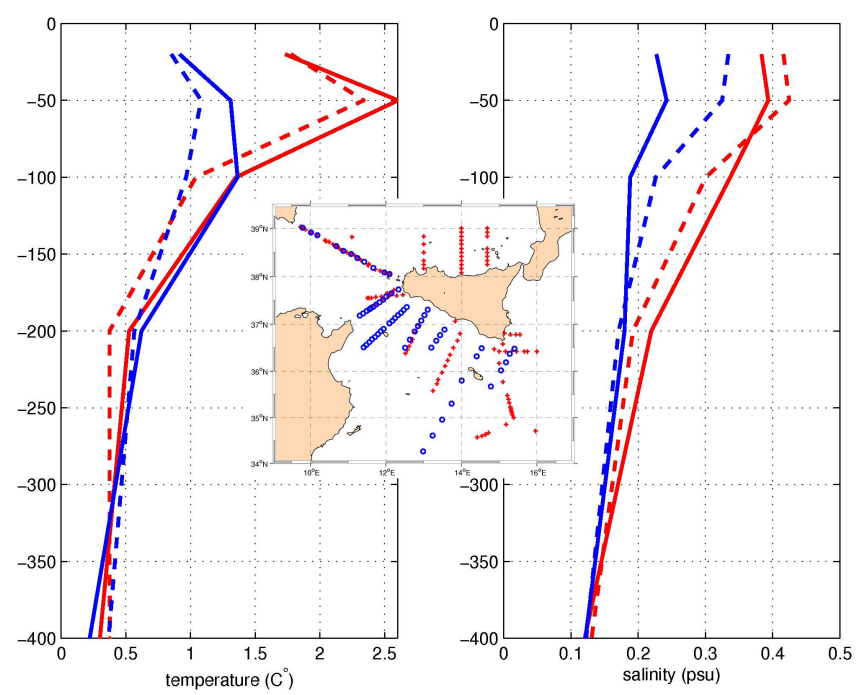

Fig. 9. RMSE profiles for AN (dashed) and SIM (full) vs. CTD observations collected in August (red) and November 2009 (blue). Left panel for temperature, right for salinity. The locations of CTD stations are also shown in the reference map.

\section{Summary and Conclusions}

The present work investigates the impact of SLA assimilation in the Sicily Channel Regional Model. The impact was studied through the intercomparison of a free-simulation (SIM) and an analysis (AN) assimilating respectively V1 SLA MyOcean along-track data. The evaluation of the analysis quality was done against an observational dataset encompassing (a) along-track V1 SLA (misfits are calculated against the analyses background, then completely independently); (b) salinity and temperature profiles, collected in August and November 2009; (c) synoptic satellite images for the detec-
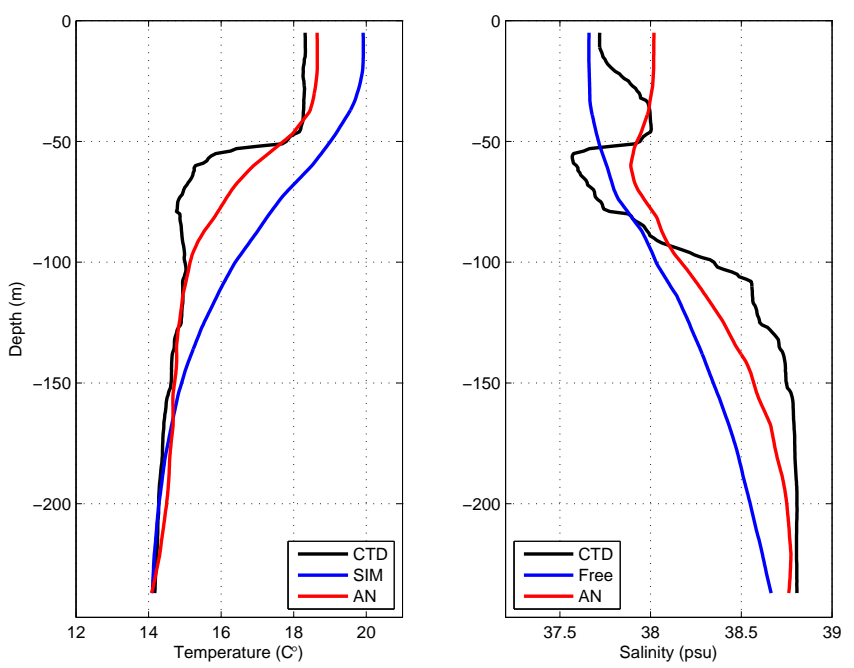

Fig. 10. Temperature (left) and salinity (right) profiles for AN (green), SIM (red) and CTD (black) for a single station $\left(11.60^{\circ} \mathrm{E}\right.$, $36.34^{\circ} \mathrm{N}$ ) during November 2009.

tion of mesoscale features and qualitative comparison with simulations.

The assimilation of SLA is proven to bring important improvements to the 2-year simulation of the circulation of the Sicily Channel area. Firstly, the model drift (in terms of misfits of free surface elevation) affecting the SIM is reduced drastically. RMSE of SLA misfits for AN (background minus observations) does not show any significant trend, while SIM RMSEs increase with time. Secondly, corrections are scattered in space accordingly with the tracks of assimilated data and are obviously larger where SIM shows larger errors. The patches with largest corrections are in the Ionian Sea and in the eastern part of the Sardinian Channel. In particular in the Ionian Sea, the corrections are associated with the incorrect reproduction of the circulation along the eastern coast of Sicily. Here, SIM often simulates the Atlantic Ionian Stream overshooting and turning northward along the eastern Sicilian coast, then again south-eastward describing an anticyclonic meander just east of Sicily. On the contrary in AN, this anticyclonic feature often disappears or is moved to the south, transformed in anticyclonic eddies. These modifications of the circulation features have been verified through satellite visible and infrared imagery.

Analysis of the fluctuating components of the velocity, performed in terms of Reynolds stresses covariance $\left.<u^{\prime} v^{\prime}\right\rangle$, shows the impact of the assimilation on the eddy/mean flow interactions. Larger differences are observed in the Ionian area where corrections have been proved to be strong. In such an area, eddy momentum flux is lower for $\mathrm{AN}$ and shows a strongly different spatial pattern that can be resembled to the signature of an anticyclonic eddy. Such changes on the fluctuating part could also imply a change in the mass transport across the channel. This effect is partially 
restrained in the present model implementation because of the OBC constraint on the net transport (operated at each open boundary). Small changes can be observed in the yearly averaged eastward (westward) transport at the Sicily Strait (Sicily-Tunisia section) that is slightly increased for AN both in 2008 and in $2009(+0.05 S v$ and $+0.1 S v$ respectively). Time series of such transports draw, on the contrary, noticeable differences between the two experiments, with AN showing a larger variability (standard deviation $\sigma$ is $0.44 \mathrm{~Sv}$ and $0.37 S v$ respectively for AN and SIM). Although these differences in transports have been evidenced, it is hard to decide which one is better, considering the difficult issue of the transport assessment and validation (even when observations are available).

Finally, the impact of the SLA assimilation on the vertical dimension is noticeable, but the results are contrasting. In August 2009, both salinity and temperature profiles are improved by the SLA assimilation in terms of RMSE (with the exception of the 0-20 m layer), while in November 2009 salinity profiles are worse for the analyses (while temperature is still improved). Considering that no TS profiles have been assimilated in the analyses, it is clear that the quality of the analyses on the vertical dimension is only a function of the vertical background error covariances. In OceanVar (Dobricic and Pinardi, 2008), the background covariances on the vertical dimension are calculated as point-by-point EOFs of pre-existing interannual model outputs. For the present work, the EOF set used is based on a 3-year model run having a similar setup as SIM experiment. Therefore, a critical point to improve the quality of the analyses on the vertical dimension is to improve the quality of the background error covariances by recomputing EOF. EOFs can be re-calculated using a longer and better model run or preferably using outputs of several experiments having even slightly different setups (in order to increase the variability described by the EOFs). Furthermore, Pujol et al. (2010) showed that the best results are obtained, once introduced the assimilation of SLA, in analyses that also assimilate vertical profile data. Therefore, to fix the questionable impact that the assimilation of SLA has shown on the vertical dimension, the future work will be addressed on the re-computation of vertical EOFs and on the assimilation of vertical profiles data.

Acknowledgements. The authors would like to thank all the people who sailed on the R/V Urania for their great contribution during the oceanographic cruises. The authors also thank the two anonymous referees, the editor and Prof. Greatbatch for precious comments and suggestions. This work was supported by EC MyOcean and REALS projects.

Edited by: A. Schiller

\section{References}

Astraldi, M., Gasparini, G. P., Sparnocchia, S., Moretti, M., and Sansone, E.: The characteristics of the water masses and the water transport in the Sicily Strait at long time scales, Dynamics of Mediterranean straits and channels, Bulletin de IInstitut Ocanographique, Monaco, CIESM Science Series n 2, 17, 95115, 1996.

Astraldi, M., Balopoulos, S., Candela, J., Font, J., Gacic, M., Gasparini, G. P., Manca, B., Theocharis, A., and Tintor, J.: The role of straits and channels in understanding the characteristics of Mediterranean circulation, Prog. Oceanogr., 44, 65-108, 1999.

Auclair, F., Marsaleix, P., and Estournel, C.: Sigma Coordinate Pressure Gradient Errors: Evaluation and Reduction by an Inverse Method, J. Atmos. Ocean. Tech., 17, 1348-1367, 2000.

Beranger, K., Mortier, L., Gasparini, G. P., Gervasio, L., Astraldi, M., and Crepon, M.: The dynamics of the Sicily Strait: a comprehensive study from observations and models, Deep-Sea Res., 2, 411-440, 2004.

Blumberg, A. and Mellor, G.: A description of a three-dimensional coastal ocean circulation model, Coastal Estuarine Science, N.S. Heaps Ed., Americ. Geophys. Union, Three-dimensional Coastal Ocean Models, 1-16, 1987.

Castellari, S., Pinardi, N., and Leaman, K.: A model study of air-sea interaction in the Mediterranean Sea, J. Mar. Syst., 18, 89-114, 1998.

Dobricic, S. and Pinardi, N.: An oceanographic three-dimensional variational data assimilation scheme, Ocean Modell., 22, 89105, doi:10.1016/j.ocemod.2008.01.004, 2008.

Dobricic, S., Pinardi, N., Adani, M., Tonani, M., Fratianni, C., Bonazzi, A., and Fernandez, V.: Daily oceanographic analyses by Mediterranean Forecasting System at the basin scale, Ocean Sci., 3, 149-157, doi:10.5194/os-3-149-2007, 2007.

Ducet, N. and Le Traon, P.-Y.: A comparison of surface eddy kinetic energy and Reynolds stresses in the Gulf Stream and the Kuroshio Current systems from merged TOPEX/Poseidon and ERS-1/2 altimetric data, J. Geophys. Res., 106, 16603-16622, doi:10.1029/2000JC000205, 2001.

Gaberšek, S., Sorgente, R., Natale, S., Ribotti, A., Olita, A., Astraldi, M., and Borghini, M.: The Sicily Channel Regional Model forecasting system: initial boundary conditions sensitivity and case study evaluation, Ocean Sci., 3, 31-41, doi:10.5194/os-331-2007, 2007.

Greatbatch, R. J., Zhai, X., Kohlmann, J.-D., and Czeschel, L.: Ocean eddy momentum fluxes at the latitudes of the Gulf Stream and the Kuroshio extensions as revealed by satellite data, Ocean Dynam., 60, 617-628, doi:10.1007/s10236-010-0282-6, 2010.

Manzella, G. M. R., Gasparini, G. P., and Astraldi, M.: Water exchange between the eastern and western Mediterranean through the Strait of Sicily, Deep-Sea Res, 35, 1021-1035, 1988.

Mellor, G. L. and Yamada, T.: Development of a turbulence closure submodel for geophysical fluid problems, Rev. Geophys. Space Phys., 20, 851-875, 1982.

Morrow, R., Coleman, R., Church, J., and Chelton, D.: Surface Eddy Momentum Flux and Velocity Variances in the Southern Ocean from Geosat Altimetry, J. Phys. Ocean., 24, 2050-2071, doi:10.1175/1520-0485(1994)024¡2050:SEMFAV ¿2.0.CO;2, 1994. 
Olita, A., Sorgente, R., Natale, S., Gaberšek, S., Ribotti, A., Bonanno, A., and Patti, B.: Effects of the 2003 European heatwave on the Central Mediterranean Sea: surface fluxes and the dynamical response, Ocean Sci., 3, 273-289, doi:10.5194/os-3273-2007, 2007.

Pinardi, N., Korres, G., Lascaratos, A., Roussenov, V., and Stanev, E.: Numerical simulation of the interannual variability of the Mediterranean Sea upper ocean circulation, Geophys. Res. Lett., 24, 425-428, doi:10.1029/96GL03952, 1997.

Pujol, M.-I., Dobricic, S., Pinardi, N., and Adani, M.: Impact of Multialtimeter Sea Level Assimilation in the Mediterranean Forecasting Model, J. Atmos. Ocean. Technol., 27, 2065-2082, doi:10.1175/2010JTECHO715.1, 2010.

Robinson, A. R., Sellschopp, J., Warn-Varnas, A., Anderson, L. A., and Lermusiaux, P. F. J.: The Atlantic Ionian Stream, J. Mar. Syst., 20, 129-156, 1999.

Smagorinsky, J.: Large eddy simulations of complex engineering and geophysical flows, Galperin, B. and Orszag., S., 1993.
Sorgente, R., Drago, A. F., and Ribotti, A.: Seasonal variability in the Central Mediterranean Sea circulation, Ann. Geophys., 21, 299-322, doi:10.5194/angeo-21-299-2003, 2003.

Sorgente, R., Olita, A., Oddo, P., Fazioli, L., and Ribotti, A.: Numerical simulation and decomposition of kinetic energy in the Central Mediterranean: insight on mesoscale circulation and energy conversion, Ocean Sci., 7, 503-519, doi:10.5194/os-7-5032011, 2011.

Tonani, M., Pinardi, N., Fratianni, C., Pistoia, J., Dobricic, S., Pensieri, S., de Alfonso, M., and Nittis, K.: Mediterranean Forecasting System: forecast and analysis assessment through skill scores, Ocean Sci., 5, 649-660, doi:10.5194/os-5-649-2009, 2009.

Vandenbulcke, L., Barth, A., Rixen, M., Alvera-Azcarate, A., Ben Bouallegue, Z., and Beckers, J. M.: Study of the combined effects of data assimilation and grid nesting in ocean models - application to the Gulf of Lions, Ocean Sci., 2, 213-222, doi:10.5194/os-2-213-2006, 2006. 